\title{
Tracing the sources of air pollutant emissions embodied in exports in the Yangtze River Delta, China: a four-level perspective
}

Article

Accepted Version

Creative Commons: Attribution-Noncommercial-No Derivative Works 4.0

Qi, X., Ma, X., Huang, X., Wang, D., Zhao, H. and Yang, H. ORCID: https://orcid.org/0000-0001-9940-8273 (2020) Tracing the sources of air pollutant emissions embodied in exports in the Yangtze River Delta, China: a four-level perspective. Journal of Cleaner Production, 254. 120155. ISSN 0959-6526 doi: https://doi.org/10.1016/j.jclepro.2020.120155 Available at https://centaur.reading.ac.uk/95934/

It is advisable to refer to the publisher's version if you intend to cite from the work. See Guidance on citing.

Published version at: https://www.sciencedirect.com/science/article/pii/S095965262030202X

To link to this article DOI: http://dx.doi.org/10.1016/j.jclepro.2020.120155

Publisher: Elsevier

All outputs in CentAUR are protected by Intellectual Property Rights law, including copyright law. Copyright and IPR is retained by the creators or other copyright holders. Terms and conditions for use of this material are defined in the End User Agreement. 


\section{www.reading.ac.uk/centaur}

\section{CentAUR}

Central Archive at the University of Reading

Reading's research outputs online 
1 Tracing the sources of air pollutant emissions embodied in exports in the Yangtze

2 River Delta, China: A four-level perspective

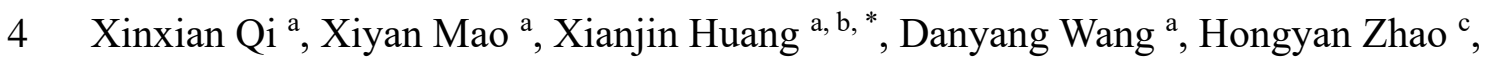

5 Hong Yang a, d, e, **

6

7 a School of Geography and Ocean Science, Nanjing University, Nanjing, Jiangsu,

8210023 , China

9 b Key Laboratory of Coastal Zone Exploitation and Protection, Ministry of Natural

10 Resources, Nanjing, Jiangsu, 210023, China

11 c Ministry of Education Key Laboratory for Earth System Modeling, Department of

12 Earth System Science, Tsinghua University, Beijing, China

13 d Collaborative Innovation Center of Atmospheric Environment and Equipment

14 Technology, Jiangsu Key Laboratory of Atmospheric Environment Monitoring

15 and Pollution Control (AEMPC), School of Environmental Science and Engineering,

16 Nanjing University of Information Science \& Technology, 219 Ningliu

17 Road, Nanjing, 210044, China

18 e Department of Geography and Environmental Sciences, University of Reading, 19 Reading, RG6 6AB, UK

21 Abstract: Investigating the net effects of foreign trade on the local environment requires a multiscale perspective. Increasingly, scholars have been investing effort to establish a global-national-local system of linkages or a local-nonlocal division of linkages. However, analysis at the megaregion level has somehow been overlooked, although megaregions play a substantial role in the context of accelerating regional integration and increasing regional pollution. This study incorporated megaregions into the existing multiscale input-output model and constructed a four-level analytical framework to analyze the emissions embodied in exports (EEE) in the Yangtze River Delta (YRD) region. Since this region pioneered the economic transition in China, this study further applies structural decomposition analysis (SDA) to investigate the structural changes in EEE. The empirical results show that EEE in the YRD region was mainly affected by local and cross-border linkages, which account for $85.1 \%$ and $9.8 \%$ of the total EEE in the region. The increase in local EEE linkages needs to be reduced by local technological innovation in sectors such as light industry and energy. To 
prevent the YRD from becoming a pollution haven for developed countries, the crossborder EEE linkage must be reduced by adjusting the production and consumption structure of light industry. Cross-regional EEE linkage can be reduced through technology upgrades in the construction sector. The trend of a decrease in intraregional linkage and an increase in cross-regional linkage indicates that YRD exports tend to be outward rather than inward oriented. The four-level framework for examining EEE offers new detailed insights into the mitigation of regional air pollution.

Keywords: Pollution embodied in exports; Multilevel perspective; Input-output model;

\section{Highlights:}

- A four-linkage framework based on MRIO was developed to trace the sources of EEE.

49 - Local and cross-border linkages accounted for most of the total EEE in the YRD.

50 - The pollution haven trend from developed countries to China's coastal regions 51 became weaker.

- $\quad$ EEE in the YRD was mainly influenced by the energy and metal manufacturing sectors.

54 - Local emission reduction relied on technology upgrade and structure optimization.

\begin{tabular}{|ll}
\multicolumn{2}{l}{ List of Acronyms } \\
EEE & Emissions Embodied in Exports \\
YRD & Yangtze River Delta \\
SDA & Structural Decomposition Analysis \\
MSIO & Multiscale Input-Output Model \\
MRIO & Multiregional Input-Output Model \\
TE & Technology Effect \\
PSE & Production Structure Effect \\
CSE & Consumption Structure Effect \\
SE & Scale Effect
\end{tabular}




\section{Introduction}

Since 2010, China has become the largest exporter worldwide, after serving as the world's factory for decades (Guan et al., 2009). Increasing overseas demand simultaneously placed an additional burden on China's eco-environmental conditions (Lin et al., 2014; Zhang et al., 2017). The term "emissions embodied in trade" in the literature captures such additional burdens (Baiocchi et al., 2012; Peters and Hertwich, 2006). Based on transnational input-output linkages and the context-dependent coefficients of emissions (Zhong et al., 2018), the trade-induced relocation of emissions across economies has been measured (Meng et al., 2018), especially between developed and developing economies (Lin et al., 2014). Studies of the emissions embodied in trade have accumulated evidence for the ongoing debate over the well-known pollution haven hypothesis (Cai et al., 2018; Yang et al., 2019a). These studies are also helpful for identifying the shared producer and consumer responsibilities for trade-induced environmental effects (Pan et al., 2008).

Nevertheless, there is increasing awareness of the multiscalar nature of the international division of labor (Antràs and Hillberry, 2012; Mao and He, 2019). That is, the network of international trade not only connects trading economies (Daumal, 2013) but also reshapes connections between interior regions (Zhong et al., 2018). When exposed to trade openness, interior regions essentially integrate with global markets in addition to domestic ones (Shao et al., 2017). To examine the environmental effects of trade at the local level, recent studies have established a multiscale input-output model (MSIO) (Chen et al., 2013; Li et al., 2016). Empirical findings from studies of urban carbon accounting (Shao et al., 2016), energy consumption (Li et al., 2019), and virtual water (Han et al., 2015) also support the rationale behind, as well as the necessity of, incorporating multiscale connections.

The multiscale perspective is especially relevant for economies with vast territories such as China, which is undergoing processes of globalization, regional integration, and economic transition (Mao and $\mathrm{He}, 2017$; Wu et al., 2017). The multiscale connections of interior regions can intertwine, working together to determine the net environmental impacts of trade openness (Hubacek et al., 2014). For instance, the export-oriented development model benefits the coastal regions of China, but they must simultaneously carry the additional environmental burden induced by increasing overseas demand from developed economies with emissions embodied in exports (EEE) 
(Liu and Wang, 2015; Su and Thomson, 2016). However, continuous development in these regions also draws resources to concentrate there and reshapes the spatial division of labor. As such, these regions are also capable of transferring emissions to other developing economies or regions and thus also of serving as the origin of embodied emissions (Davis and Caldeira, 2010; Guo et al., 2012). Regarding this point, previous studies at different scales provide mixed empirical findings. Some studies reveal that inland regions in China have relatively lax environmental regulations, which lead to the transfer of the environmental burden from the coast to the inland (Yang et al., 2012; Zhu et al., 2014). In contrast, others find that the unique advantages of coastal regions due to locational fundamentals supports the continuous development of both traditional and emerging sectors (Wang and Zhao, 2015). Considering the above, examining the net effects of multiscale linkages is essential to investigate the effects of trade openness on the regional environment.

The question that follows is how many different scales should be considered to capture the net effects of embodied emissions? Early studies at the national level consider a nation to be a homogeneous entity and allow internal inequality to be easily ignored (Liu and Wang, 2017; Stern, 2004). Recent studies shift their focus from the national level (Feng et al., 2013) to the level of subnational regions, such as provinces (Meng et al., 2013) or cities (Chen et al., 2013). Multiscale linkages tend to cover the division of both local and nonlocal linkages or the hierarchical systems of globalnational-local linkages ( $\mathrm{Li}$ et al., 2018a). However, considering the accelerating pace of regional integration, neither the local-nonlocal division nor the global-nationallocal system directly incorporates the level of megaregions. For instance, in some developed regions in China, such as Beijing-Tianjin-Hebei, the internal region has formed a division of labor, cooperation and interdependency. Due to Beijing's and Tianjin's high imports from Hebei, industrial production in Beijing and Tianjin has led to the transfer of more pollutant emissions to Hebei (Zhao, et al., 2016a). In this way, despite the reduced emissions from Beijing and Tianjin, pollution emissions still remain in the region, and the pollution problem for the whole region has not been resolved, with the consequence of a "local reduction but regional rise" in emissions. Thus, it is necessary to incorporate the regional level into the conventional MSIO, which tends to be at the city level (Lin et al., 2017). Correspondingly, this study incorporates the megaregion level and proposes a four-scale framework, covering the local, regional, national, and global levels. 
For the megaregion level, this study adopted the Yangtze River Delta (YRD) as a case. The YRD has pioneered China's opening up policy thanks to its local advantages and the support of governmental policies. The YRD fosters the largest city cluster nationwide, accounting for $20.4 \%$ of the national gross domestic product (GDP) and $37.3 \%$ of China's exports in 2017 (NBS, 2018). The YRD also serves as a portal connecting the overseas market and the inland regions. In addition, two regional and national development plans intersect in the YRD, namely, the Belt and Road Initiative and the Yangtze River Economic Belt (NDRC, 2016). Therefore, compared with the Beijing-Tianjin-Hebei region and the Pearl River Delta region, the YRD has more links with overseas and inland regions. Nevertheless, rapid economic growth and

134 urbanization make the YRD one of the largest emitters in China and exposes it to a high 135 risk of environmental degradation (Li et al., 2018b; Meng et al., 2019), resulting in the 136 YRD region being one of the most seriously polluted metropolitan regions in China 137 (Liu et al., 2017; Cheng et al., 2019), and industry plays the biggest part in the problem 138 (Zheng et al., 2016). Furthermore, there are large spatial variations in pollution 139 emissions within the YRD region (Cheng et al., 2019). Energy intensity and energy 140 structure were identified as the two main drivers to mitigate emissions in the YRD 141 region (Xu et al., 2017; Zhu et al., 2017). It is worth noting that one of the limitations 142 of previous studies is that they considered the YRD as a static economy, ignoring its 143 strong external economic linkages. Recently, interprovincial air pollution transfer in the 144 YRD has received increasing attention, such as in the electricity sector (Li et al., 2018), 145 but whole-sector and multiscale research is still urgently needed to form an integrated 146 scheme to meet the sustainable targets in the YRD region. The government has been 147 aware of severe environmental problems and has implemented measures to address 148 these challenges (Yang et al., 2015), but there is still much to be done to completely 149 clean the polluted environment (Yang et al., 2019b). The "Ten Measures for the 150 Prevention and Control of Atmospheric Pollution" released by China's State Council in 1512013 proposed that the treatment of environmental pollution required integrated 152 regional governance, and the "Ten Measures" established a joint control mechanism in 153 Beijing-Tianjin-Hebei, the YRD, and the Pearl River Delta region. Therefore, the YRD 154 region provides an experimental site for environmental pollution control under multiple 155 economic linkages.

156 Overall, this study aimed to develop a four-scale analytical framework to analyze 157 regional export-related pollution problems in the YRD and propose regional emission 
158

159

160

161

162

163

164

165

166

167

168

169

170

171

172

173

174

175

176

177

178

179

reduction policy recommendations based on a decomposition analysis of scale and sectoral EEE shifts. $\mathrm{SO}_{2}, \mathrm{NOx}$ and $\mathrm{PM}_{2.5}$ are the main air pollutants (Zhao, et al., 2016a) and the key prevention and control objectives in China (China State Council, 2013), so they were selected as emission equivalents in this study. The multiregional input-output (MRIO) tables of 2007, 2010 and 2012 for 30 provinces (excluding Tibet, Hong Kong, Macau and Taiwan due to data limitations) and 30 economic sectors were analyzed. The objectives of this study are to 1) analyze the scale and sectoral characteristics of EEE in four linkages over time; 2) identify the determinants of scale and sectoral EEE shifts in the four linkages by employing structural decomposition analysis (SDA); and 3) propose specific recommendations for regional pollution reduction based on the results of the four-scale framework.

\section{Materials and methods}

This study constructed a four-scale research framework to track the sources of EEE in the YRD, connecting EEE linkages at multiple scales and between multiple sectors based on MIRO tables. SDA was applied to decompose the EEE shifts across scales and sectors (Fig. 1).

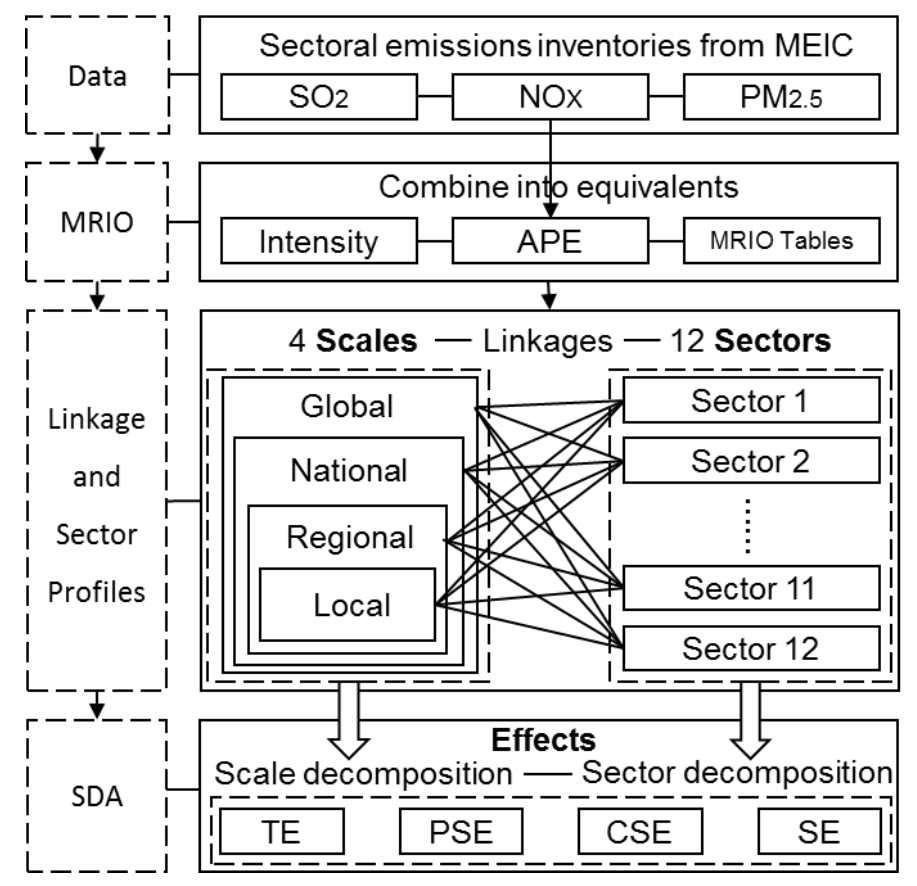

Fig. 1 Research framework of this study. MEIC is a multiscale emission inventory model; MRIO is a multiregional input-output analysis; APE is atmospheric pollutant equivalents; $\mathrm{SDA}$ is a structural decomposition analysis; $T E$ is the technology effect; $P S E$ is the production structure effect; $C S E$ is the consumption structure effect; and $S E$ is the scale effect. 


\subsection{Data on production-based pollution emissions}

Sectoral emission inventories in 2007, 2010, and 2012 in Shanghai, Jiangsu, and Zhejiang in the YRD region were obtained from the China Multiscale Emission Inventory Model (MEIC) database developed and managed by Tsinghua University, China (http://www.meicmodel.org/). The MEIC is a bottom-up emission inventory model that covers more than 700 anthropogenic emission sources (Li et al., 2014; Li et al., 2017; Liu et al., 2015). Emission sources are classified based on sector, fuel/product, combustion/process technology, and end-of-pipe control technology. The emission data were mapped to 30 sectors defined in the MRIO model (Zhao et al., 2015).

To measure the comprehensive effect of various atmospheric pollutants, this study adopted the "pollutant equivalent" method proposed by China's Ministry of Ecology and Environment, considering the impact on ecological systems, toxicity to organisms and technical feasibility of removing each pollutant (Yang and Wang, 1998). Three main types of air pollutants, $\mathrm{SO}_{2}, \mathrm{NO}_{\mathrm{x}}$, and $\mathrm{PM}_{2.5}$, were selected from the MEIC inventory, and these three pollutants were combined into a new parameter called atmospheric pollutant equivalents (APE). Based on China's official documents about the pollution charge schedule (SDPC et al., 2003), the conversion coefficients of $\mathrm{SO}_{2}$, $\mathrm{NO}_{\mathrm{x}}$, and $\mathrm{PM}_{2.5}$ to APE are 0.95, 0.95 and 4, respectively, which means that $1 \mathrm{~kg} \mathrm{APE}$ is equal to $0.95 \mathrm{~kg} \mathrm{SO}_{2}, 0.95 \mathrm{~kg} \mathrm{NO}_{\mathrm{x}}$ and $4 \mathrm{~kg} \mathrm{PM} 2.5$. This study combined $\mathrm{SO}_{2}, \mathrm{NO}_{\mathrm{x}}$, and $\mathrm{PM}_{2.5} \mathrm{EEE}$ as follows:

$$
E E E=\sum_{k=1}^{n} E E E_{i} / R_{k}
$$

where $R_{k}$ represents the conversion coefficient between different pollutants $k$ and the equivalents.

\subsection{Multiregional input-output model (MRIO)}

The socioeconomic and environmental effects of products and services include direct and indirect effects. The input-output model established by Leontief (1974) explains the relationship between sectors and regions, and it has been widely used to track the indirect environmental impacts caused by upstream production. Based on China's MRIO tables in 2007 and 2010 compiled by Liu et al. $(2012 ; 2014)$ and in 2012 compiled by China Emission Accounts and Datasets (Mi et al., 2017), this study extracted key information and compiled the YRD input-output table. The YRD three- 
zone model contains detailed information on 30 interprovincial trade and international

211 export sectors.

212 Table A1 shows the model structure. The balance of money flow in each row is 213 calculated as follows (Leontief, 1974):

$$
\sum_{r=1}^{3} \sum_{j=1}^{30} Z_{i j}^{r s}+\sum_{s=1}^{28} y_{i}^{r s}=x_{i}^{r}
$$

214 where $Z_{i j}^{r s}$ represents the demand of sector $j$ in province $s$ for sector $i$ in province $215 r$, which is the intermediate input; $y_{i}^{r s}$ represents the production in sector $i$ in province $216 r$ and final consumption in province $s$; and $x_{i}^{r}$ represents the total output of sector $i$ in 217 province $r$;

$$
a_{i j}^{r s}=Z_{i j}^{r s} / x_{i j}^{s}
$$

218 where $a_{i j}^{r s}$ represents the direct consumption coefficient of the unit production of 219 sector $j$ in province $s$ produced by sector $i$ in province $r$. Equations 2 and 3 are combined to form Equation 4:

$$
A x+y=x
$$
where $A x$ represents $\sum_{r=1}^{3} \sum_{j=1}^{30} a_{i j}^{r s} x_{i j}^{s}, y$ represents $y_{i}^{r s}$, and $x$ represents $x_{i}^{r}$. Equation 4 is converted into total output as follows:

$$
x=(I-A)^{-1} y
$$

where $(I-A)^{-1}$ is the Leontief inverse matrix, which means that producing a unit of sector $j$ 's final product requires the sum of one unit product of the sector and the intermediate products of all other sectors. $I$ represents the identity matrix, and $A$ is the matrix of $a_{i j}^{r s}$. By calculating the emission intensity of each region, EEE is calculated as follows (Zhang et al., 2018a):

$$
E E E=F x
$$

$$
E E E=F(I-A)^{-1} y
$$

where $F$ is the discharge intensity of the exit.

\subsection{Multi EEE linkage analytical framework based on the region}

230 Environmental pollution in an open economic area is often affected on multiple 231 scales (Mao and He, 2017). Studies have found that an open region's embodied emissions come from four linkages: 1) cross-border (Liu and Wang, 2015), 2) cross- 
regional (Zhang et al., 2018b), 3) intraregional (Zhao, et al., 2016a), and 4) local

234 (Zhong et al., 2017). In this study, an analytical framework of regional embodied 235 emissions was established based on the calculation of EEE in four export linkages 236 related to the region. These four linkages correspond to the four scales of EEE: global, 237 national, regional and local (Fig. 2). In our study, the four linkages are defined as 238 follows: the first linkage from the global scale refers to the three provinces (Jiangsu, Zhejiang, and Shanghai) in the YRD as a whole, which produce embodied emissions through international trade. The second linkage from the domestic scale refers to the embodied emissions produced by the three provinces in the YRD as a whole and exported to other provinces in China (except Hong Kong, Macao, Taiwan and Tibet due to data limitations). The third linkage from the regional scale refers to the embodied emissions produced by intraregional exports among local areas within the YRD region.

The fourth linkage at the local level refers to the embodied emissions produced by local production and consumption.
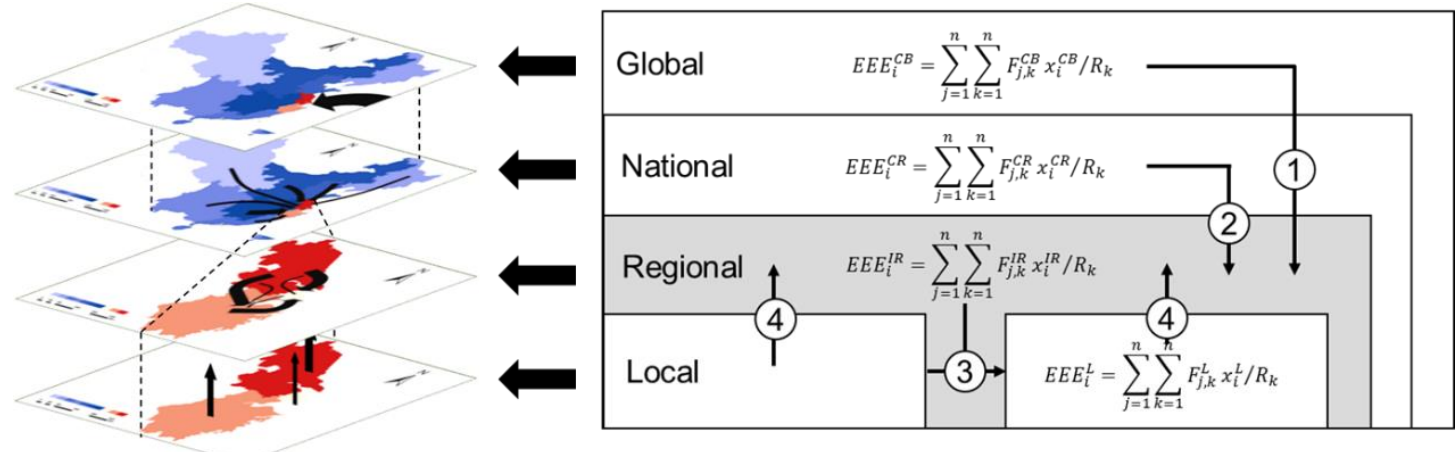

Fig. 2 Four-level analytical framework of $E E E$ based on region, where (1) $E E E_{i}^{C B}$ represents $E E E$ based on the cross-border linkage, (2) $E E E_{i}^{C R}$ represents EEE based on the cross-regional linkage, (3) $E E E_{i}^{I R}$ represents $E E E$ based on the intraregional linkage, and (4) $E E E_{i}^{L}$ represents $E E E$ based on the local linkage.

\subsection{Structural decomposition analysis}

An SDA of emission equivalents embodied in trade can provide further insights into the factors contributing to the changes in embodied emissions ( $\mathrm{Xu}$ and

256 Dietzenbacher, 2014). Such an approach has been used in previous studies (Lan et al., 257 2016; Mi et al., 2018; Zhao, et al., 2016b). To quantify the forces driving the change in 258 EEE, Equation 7 can be broken down into Equation 8 as follows: 


$$
E E E=F(I-A)^{-1} \frac{y}{x_{i}^{r}} x_{i}^{r}=T E \cdot P S E \cdot C S E \cdot S E
$$

where TE represents the technology effect; PSE represents the production structure effect; CSE represents the consumption structure effect; and $S E$ represents

261 the scale effect. The environmental effects of trade depend mainly on the overall ratio 262 of the scale, structure and technological effects (Antweiler et al., 2001). A region's 263 emissions depend on its position and participation level in supply chains (Meng et al., 264 2013), while the technical and structural effects of exports are the main factors causing 265 changes in EEE (Duan and Jiang, 2017).

266 The bipolar decomposition method (Dietzenbacher and Los, 1998; Meng et al., 267 2018) is used as an approximation of the average of all $n$ ! decompositions. The 268 influencing factors of $E E E$ are decomposed as follows:

$\triangle E E E=f(\triangle T E)+f(\triangle P S E)+f(\triangle C S E)+f(\triangle S E)$

$f(\triangle T E)=1 / 2[\triangle T E \cdot P S E(0) \cdot \operatorname{CSE}(0) \cdot \operatorname{SE}(0)+\triangle T E \cdot P S E(1) \cdot \operatorname{CSE}(1) \cdot S E(1)]$

$f(\triangle P S E)=1 / 2[T E(1) \cdot \triangle P S E \cdot \operatorname{CSE}(0) \cdot S E(0)+T E(0) \cdot \triangle P S E \cdot \operatorname{CSE}(1) \cdot S E(1)]$

$f(\triangle C S E)=1 / 2[T E(1) \cdot P S E(1) \cdot \triangle C S E \cdot S E(0)+T E(0) \cdot P S E(0) \cdot \triangle C S E \cdot S E(1)]$

$f(\triangle S E)=1 / 2[T E(1) \cdot P S E(1) \cdot \operatorname{CSE}(1) \cdot \triangle S E+T E(0) \cdot P S E(0) \cdot \operatorname{CSE}(0) \cdot \triangle S E]$

\section{Results}

Based on the established four-level analytical framework, this study characterized the spatial and sectoral changes of EEE in the YRD region and identified the key

272 linkages and sectors affecting EEE changes. To explore the causes of these shifts, the four linkages were decomposed by SDA. To propose more specific emission reduction measures, the key sectors were also decomposed by SDA.

\subsection{EEE profiles in the YRD region in the four linkages}

Figure 3 shows the EEE changes in the entire region and the four linkages. The total EEE in the YRD region experienced a decreasing and then an increasing trend from 2007 to 2012, with a peak at 3,380 gigagrams (Gg) in 2012 (Fig. 3). The regional experienced sustained growth, peaking at $2,877 \mathrm{Gg}$ in 2012 . The proportion of local 
281 EEE in total EEE in the region also increased, accounting for $85.1 \%$ in 2012. The cross282 border EEE linkage decreased by $41.0 \%$ from 2007 to 2012 , contributing only $9.8 \%$ to 283 the total EEE in the region in 2012. However, the EEE changes in the intraregional and 284 cross-regional linkages were not as obvious as the changes in the other two linkages. 285 Similar to the cross-border linkage, intraregional EEE decreased by more than $70.1 \%$ 286 from 2007 to 2012 . In contrast, cross-regional EEE increased by nearly $78.7 \%$ between 2872007 and 2012, accounting for nearly $4.8 \%$ of the total EEE in 2012. In general, from 288 the perspective of the EEE changes in the four linkages, local linkages continued to 289 have the highest proportions. The impact of cross-border and intraregional linkages on 290 the regional environment decreased, while the influence of cross-regional linkage on 291 the regional environment increased.

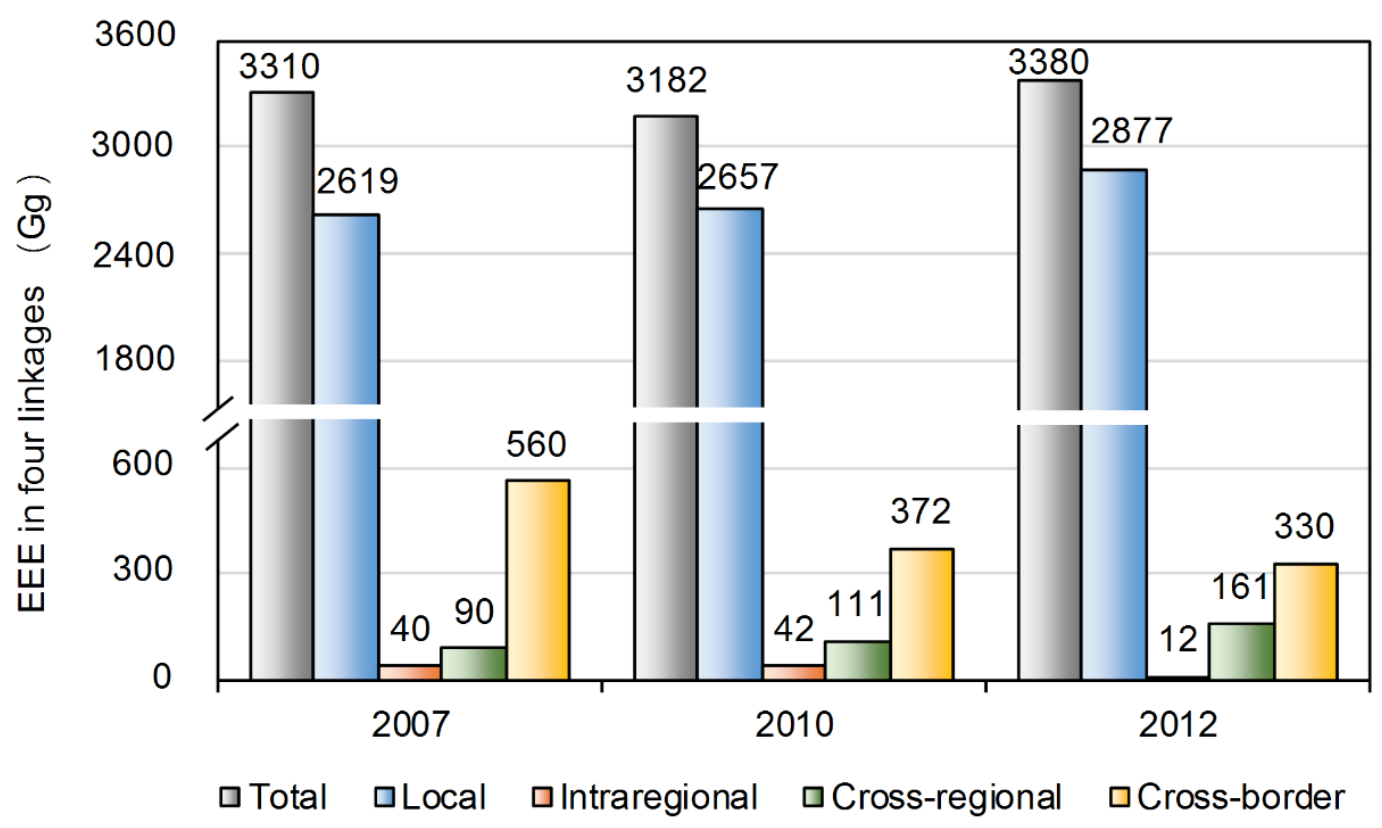

Fig. 3 EEE changes in the YRD based on four linkages 


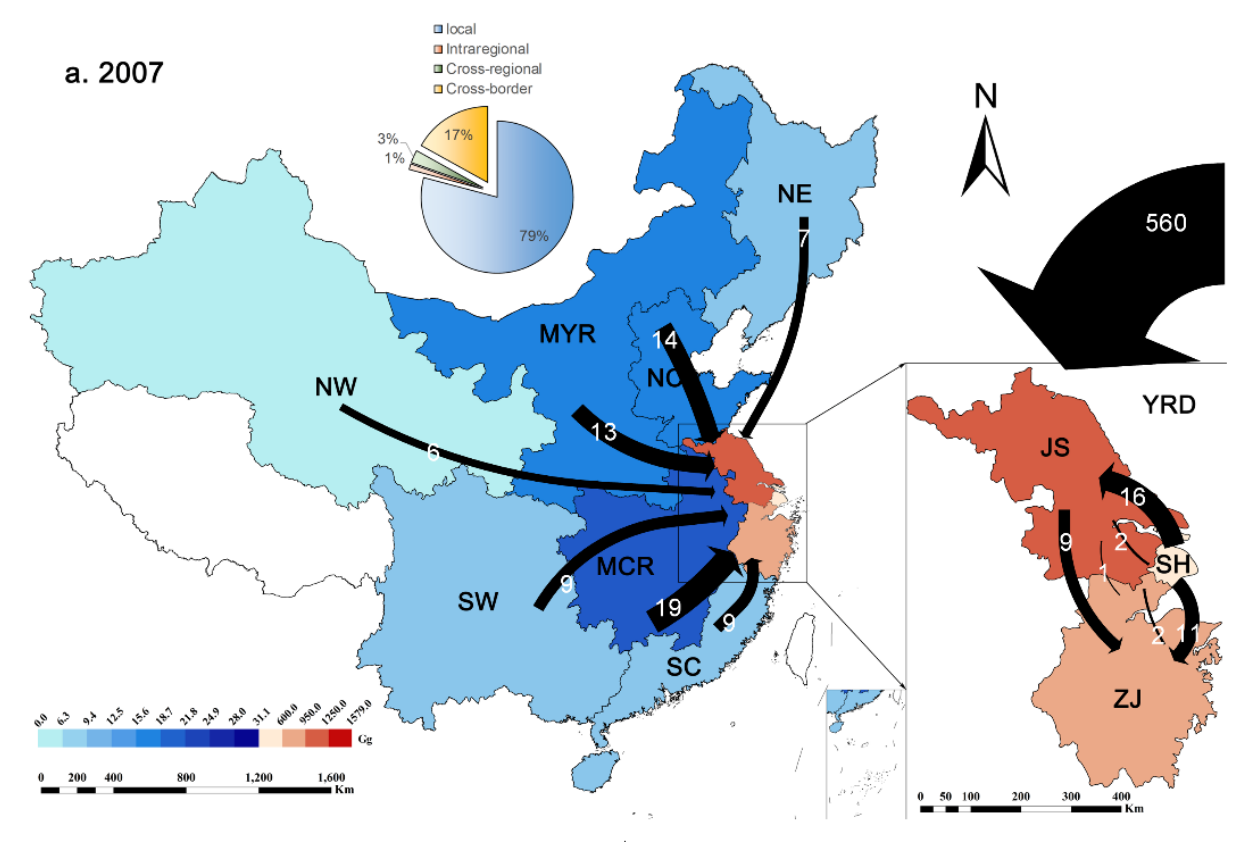

294

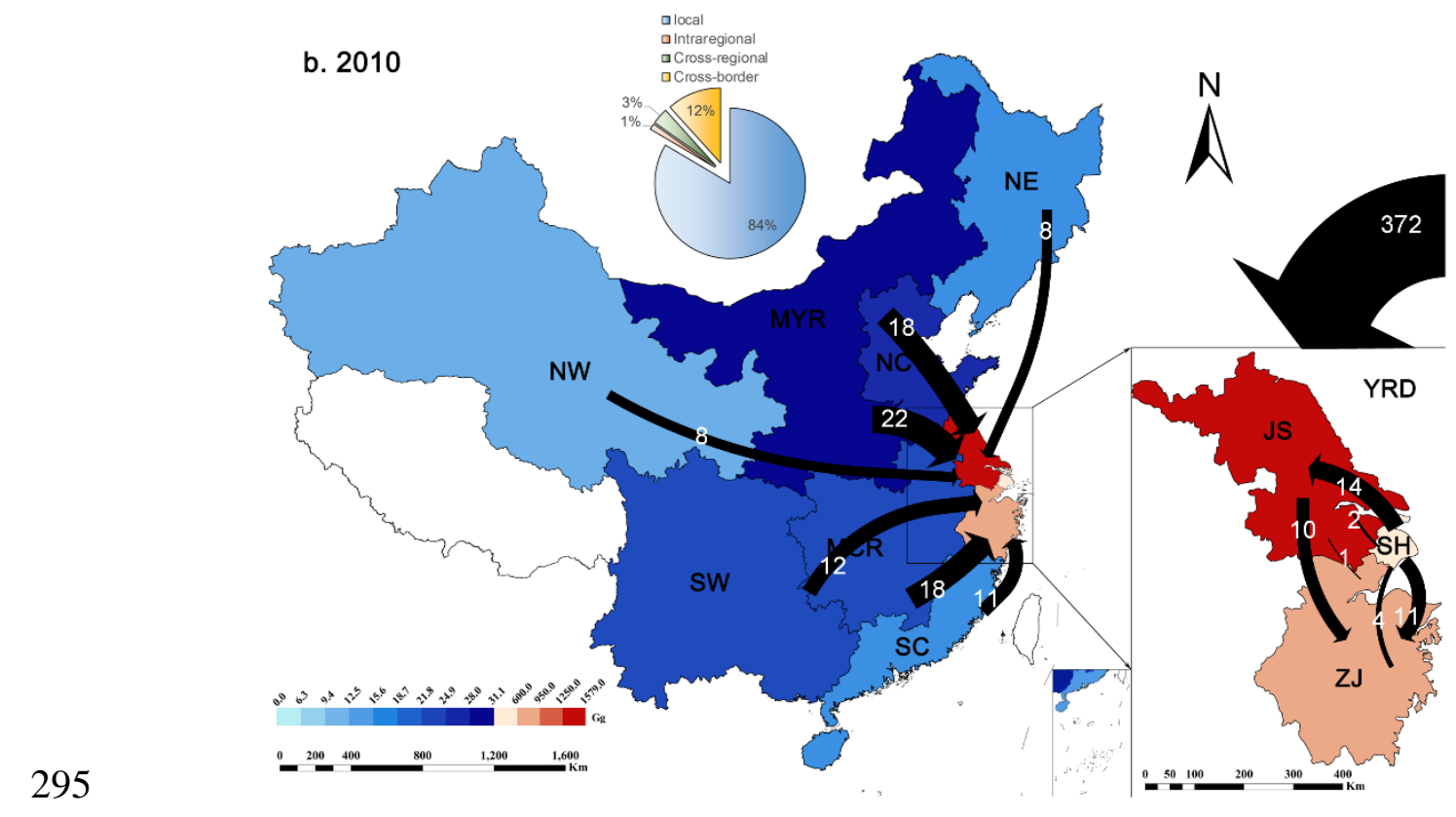




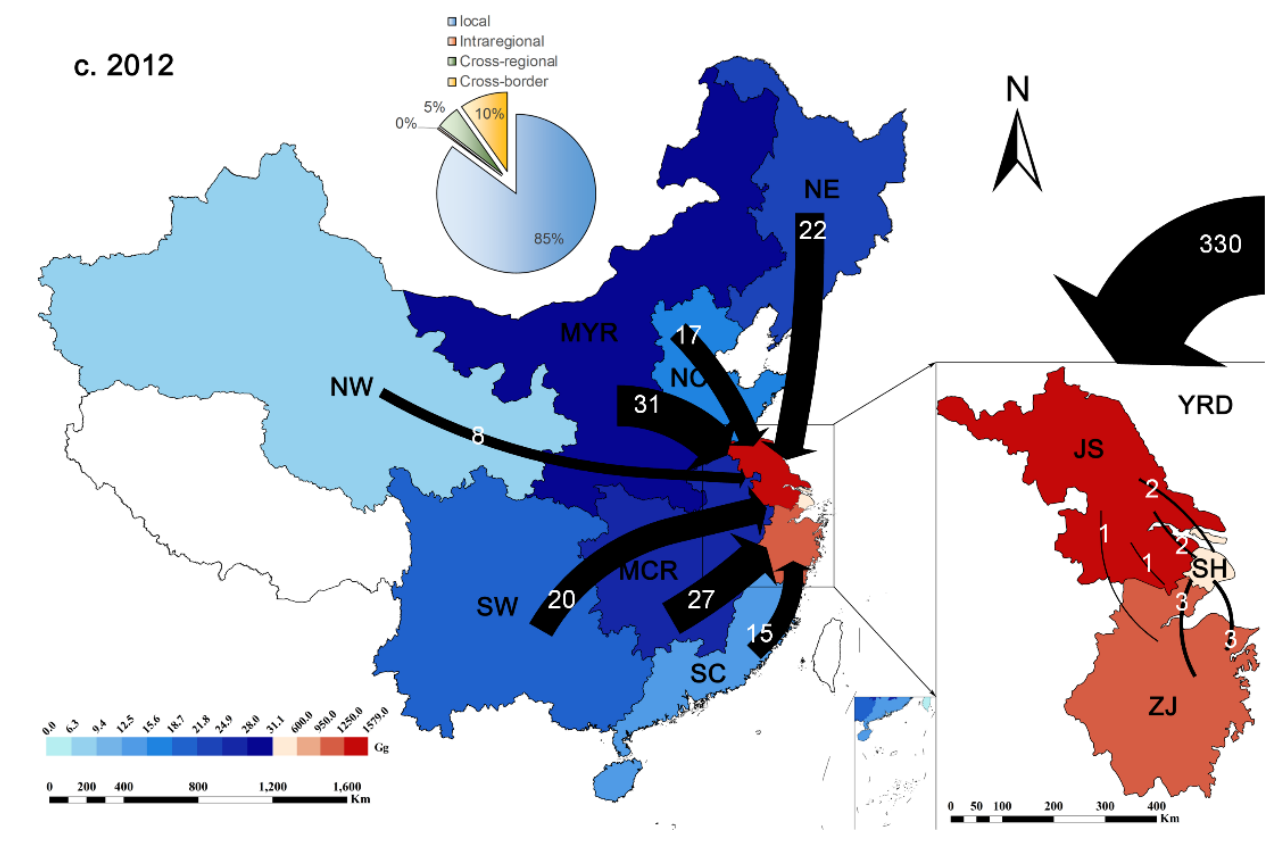

298 Fig. 4 Spatiotemporal changes in EEE in the YRD. EEE in the YRD region in 2007 (a), 2992010 (b), and 2012 (c). The thickness and number of the arrows represent the amount 300 of EEE transferred. SH is Shanghai municipality; JS is Jiangsu Province; ZJ is Zhejiang 301 Province; NE is Northeast China; NC is northern coastal China; SC is southern coastal China; MYR is middle of the Yellow River; MCR is middle of the Yangtze River; NW is Northwest China; SW is Southwest China; and YRD is the Yangtze River Delta.

From the perspective of the local linkage, the local EEE in the YRD region generally experienced an increasing trend, with spatial variations between the three provinces (Fig. 4). The local EEE in Shanghai decreased by 26.3\% from 2007 to 2012, accounting for only $11.1 \%$ of the YRD's local EEE in 2012. In contrast, the local EEE in Jiangsu gradually increased, contributing 54.9\% to the YRD's local EEE in 2012. During the same period, the local EEE in Zhejiang experienced an increase and then a decrease, accounting for 34.1\% of the YRD's local EEE in 2012.

The intraregional EEE linkage in the YRD showed a gradual decreasing trend (Fig.

313 4). In particular, the intraregional EEE from Jiangsu and Zhejiang declined markedly, 314 by $76.2 \%$ and $80.4 \%$, respectively, from 2007 to 2012 . In terms of intraregional linkage, 315 Jiangsu experienced more intraregional EEE from the other two provinces, while the 316 EEE in Shanghai and Zhejiang gradually lessened.

317 The regional EEE across the YRD caused by the cross-regional linkage continued 318 to increase over the period due to contributions from all regions across China (Fig. 4). 
319 The most marked increase appeared in Northeast China, the middle of the Yellow River 320 and Southwest China, which saw increases of $218.6 \%, 144.8 \%$ and $113.1 \%$, 321 respectively, during the period of 2007-2012. Slow increases occurred in southern 322 coastal China, the middle of the Yangtze River, Northwestern China, and northern 323 coastal China, where EEE increased by $68.3 \%, 44.1 \% 31.3 \%$, and $22.8 \%$, respectively. 324 The geographic center of gravity of the cross-regional EEE linkage moved 127 kilometers to the northeast between 2007 and 2012.

Regarding the cross-border EEE linkage in the YRD region, international exports in the YRD region gradually reduced between 2007 and 2012. Zhejiang and Shanghai

328 had larger deceases (60.0\% and 55.7\%), while Jiangsu had a smaller reduction (33.9\%).

\subsection{Sector-specific EEE in the YRD}

330 The analyses of the EEE of different sectors at four scales can identify the effects 331 of each sector on the EEE in the YRD region (Fig. 5). In terms of the overall EEE 332 situation in the YRD region, sector 8 (energy industry) had the largest EEE. This sector 333 experienced a decrease and then an increase from 2007 to 2012, accounting for 37.5\% 334 of the EEE in the YRD region in 2012 and the largest proportion of EEE at the local 335 level (44.0\%). The environmental impact of sector 9 (construction) on the YRD region 336 had the fastest growth rate, growing 91.5\% from 2007 to 2012, and it was a key sector 337 in the cross-regional linkage, accounting for $42.7 \%$. Sector 10 (transportation) had the 338 largest rate of decrease $(-16.8 \%)$, while sector 12 (other services) had the largest 339 increase $(+110.2 \mathrm{Gg})$ and contributed the largest proportion at the intraregional level 340 (34.3\%). Sector 6 (metal and nonmetal products) had the largest reduction in EEE ($34183.1 \mathrm{Gg}$ ), and it made a marked contribution to EEE in the YRD region, accounting for $34218.6 \%$ of the EEE in 2012. Sector 4 (light industry products) accounted for most of the 343 EEE due to cross-border linkage (32.8\%). 


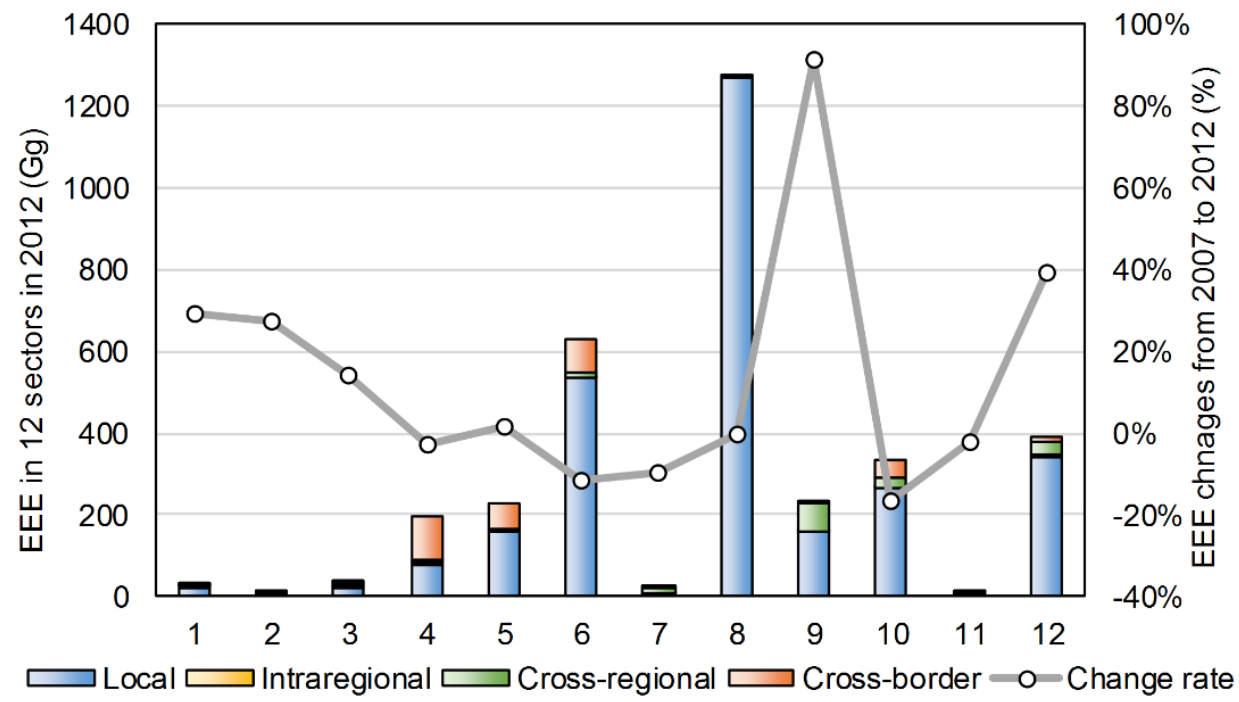

Fig. 5 EEE in 12 sectors at four levels in 2012 and changes in EEE by sector from 2007 to 2012.

346 Numbers 1 to 12 represent agricultural products, mining products, foods, light industry products, 347 chemical products, metal and nonmetal products, equipment, energy, construction, transportation, 348 wholesale and retailing, and other services, respectively. See appendix Table A2 for more details.

EEE had obvious sector-specific characteristics at the four scales. The change in the total EEE in the YRD region from 2007 to 2012 was mainly affected by the local and cross-border linkages of EEE (Fig. 6). The increase in local EEE was mainly caused

353 by labor-intensive industries, such as sector 4 (light industry products) $(+35.1 \mathrm{Gg})$, 354 sector 9 (construction) ( $+47.5 \mathrm{Gg}$ ), and sector 12 (other services) (+91.2 Gg), and by 355 capital-intensive industries, such as sector 5 (chemical products) $(+16.5 \mathrm{Gg})$, sector 8 356 (energy) $(+42.9 \mathrm{Gg})$, and sector 10 (transportation) $(+52.4 \mathrm{Gg})$. The decrease in the 357 cross-border EEE linkage was mainly due to the decline in sector 10 (transportation), 358 sector 4 (light industry products), and sector 6 (metal and nonmetal products). Among 359 these, sector 10 (transportation) saw the largest reduction $(-128.3 \mathrm{Gg})$. In contrast, the 360 intraregional and cross-regional EEE linkages experienced minor changes. The increase 361 in cross-regional EEE was mainly caused by sector 9 (construction), while the decrease 362 in intraregional linkage was primarily caused by sector 8 (energy). 


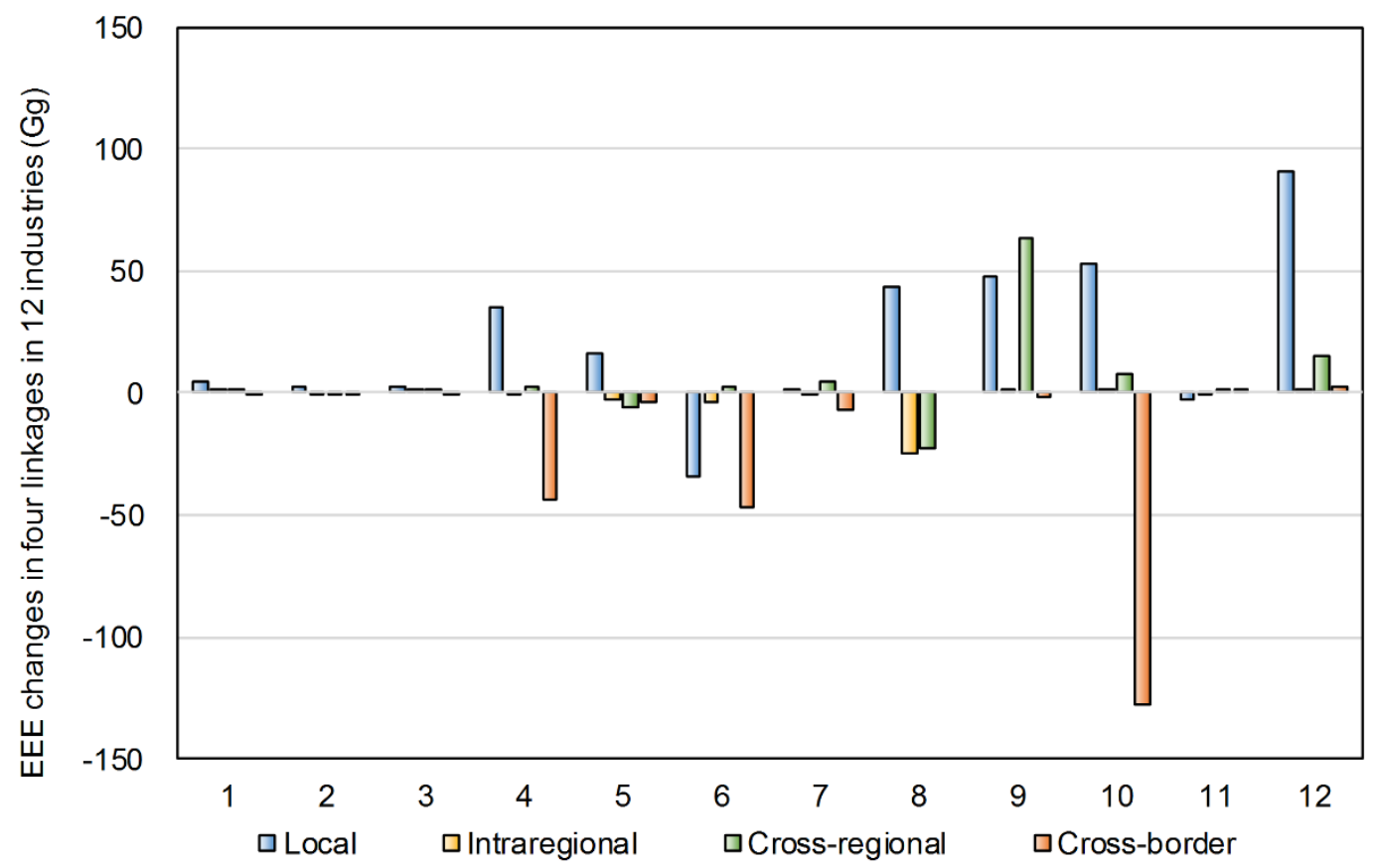

Fig. 6 Changes in EEE at four levels in 12 sectors from 2007 to 2012. Numbers 1 to 12 represent agricultural products, mining products, foods, light industry products, chemical products, metal and nonmetal products, equipment, energy, construction, transportation, wholesale and retailing, and other services, respectively. See appendix Table A2 for more details.

\subsection{The restructuring of EEE in the YRD region}

To analyze the influencing factors of EEE in the YRD region at the four scales from 2007 to 2012, SDA was conducted to deconstruct the factors into four types of effects: technical effect $(T E)$, production structure effect (PSE), consumption structure effect $(C S E)$ and scale effect $(S E)$.

The local EEE in the YRD region experienced a continuous increase (Fig. 7a), growing by $1.4 \%$ from 2007 to 2010 and by $8.3 \%$ from 2010 to 2012 . The local EEE was mainly affected by $T E$ and $S E$. Although the increase brought by $S E$ weakened from $52.9 \%$ to $33.3 \%, T E$ did not show an obvious effect (decreasing from $44.3 \%$ to 19.4\%), with the consequence being the continuous increase in local EEE in 2012.

The intraregional EEE linkage in the YRD region experienced an increase of 3.0\% from 2007 to 2010 and a significant decrease of $71.0 \%$ from 2010 to 2012 (Fig. 7b). After 2010, the main reason for the decrease in intraregional EEE linkage was the marked reduction in CSE (76.2\%) in the region. Obvious changes in the consumption structure have appeared among cities in the YRD region.

384 from 2007 to 2010 and $44.7 \%$ after 2010 . The continuous increase in cross-regional 
EEE was affected by TE, CSE and $S E$, and the main reason for the continuous increase was the decrease in TE. From 2007 to 2010, the decrease in $T E$ was not balanced by the increase in CSE and SE. After 2010, TE decreased from 53.3\% to $14.4 \%$. The YRD region was one of the most technologically advanced regions in China. Other lessdeveloped regions, for example, inland China, increasingly relied on technology transfer from the YRD region, leading to the increase in cross-regional EEE.

The cross-border EEE linkage in the YRD region gradually decreased due to the influence of the international economic situation (Fig. 7d), while the reasons for the reduction in cross-border EEE linkage varied. From 2007 to 2012, EEE at this level 394 decreased by $33.6 \%$, mainly due to the contribution of TE and PSE. From 2010 to 2012, 395 the reduction declined to $11.2 \%$. During this period, $T E$ decreased from $29.5 \%$ to $13.2 \%$, 396 while CSE grew from $2.5 \%$ to $8.9 \%$. Thus, the reduction in cross-border EEE linkage 397 depended on technology upgrading and the optimization of the production structure of 398 export products.
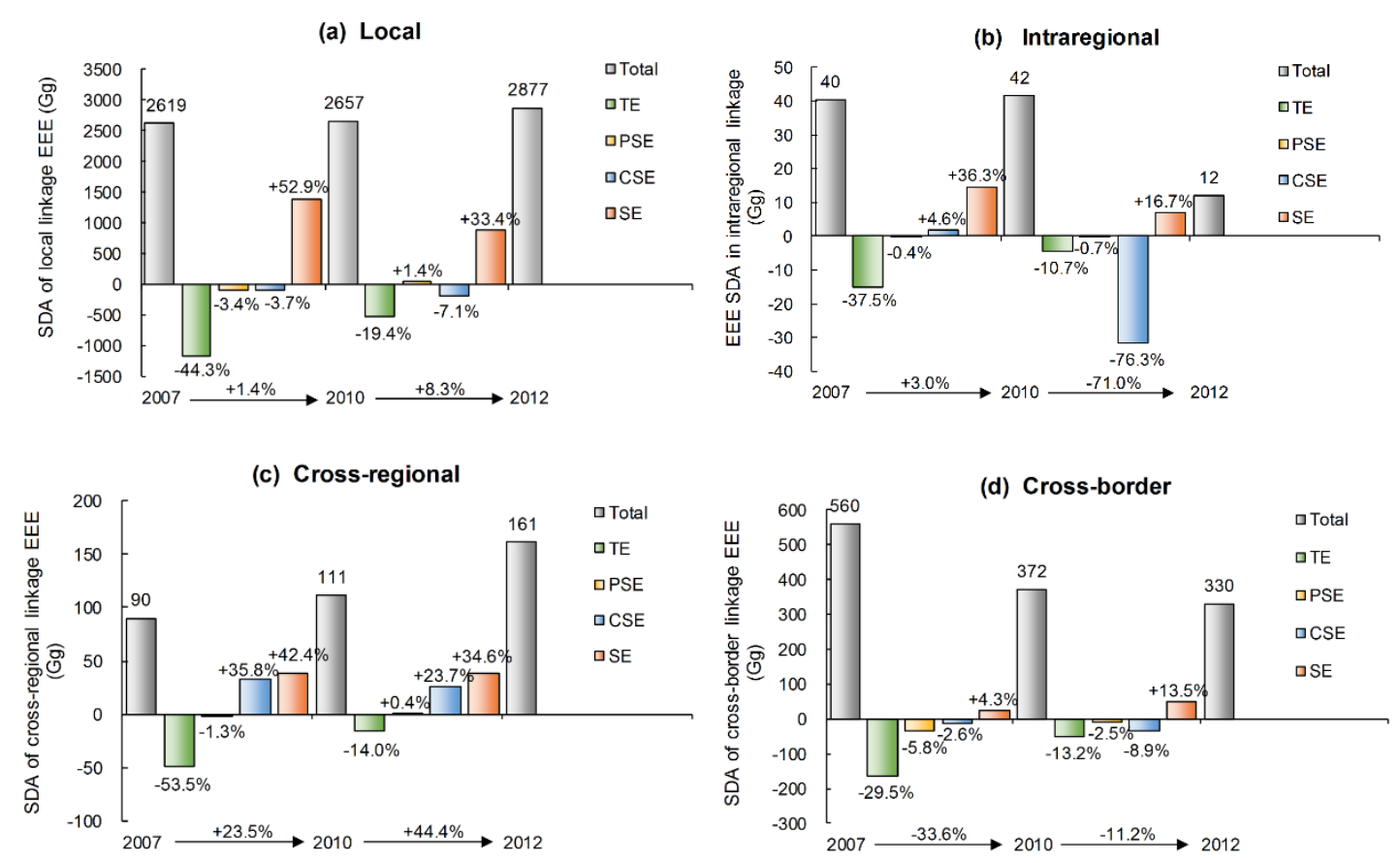

403 Fig. 7 Structural decomposition analysis (SDA) of EEE in the four linkages from 2007 404 to 2012: (a) local EEE, (b) intraregional EEE, (c) cross-regional EEE, and (d) cross405 border EEE. TE means technical effect, PSE means production structure effect, CSE 406 means consumption structure effect and $S E$ means scale effect. 
Six sectors were selected for further decomposition. These sectors contributed to the vast majority (90.1\%) of the EEE in the YRD region (Fig. 5); among them, sectors 8 and 6 accounted for $37.5 \%$ and $18.6 \%$, respectively. Furthermore, sectors 12 and 9 experienced the largest increase $(+110.2 \mathrm{Gg}$ and $+109.5 \mathrm{Gg})$, while sectors 6 and 10 saw the largest decrease $(-83.1 \mathrm{Gg}$ and $-63.4 \mathrm{Gg}$ ) (Fig. 6). Therefore, these sectors, which include capital-intensive sectors $(6,8,9$ and 10) and labor-intensive sectors (4 and 12), had a crucial impact on EEE transfer at the four scales.

As shown in Figure 6, sector 4 (light industry) mainly affected the increase in the local EEE linkage and the decrease in the cross-border EEE linkage in the YRD. In addition, sector 4 had the largest proportion of cross-border EEE linkage. From the SDA results (Fig. 8a), the decline in sector 4 in 2007-2010 was mainly due to the large decline in $T E$ in the local and cross-border linkages, while the increase from 2010 to 2012 was mainly due to the $S E$ formed by local and cross-border linkages. In addition, $T E$ lost its decreasing effect in the cross-border linkage in 2010-2012. Obviously, the local and cross-border linkages were the key linkages of sector 4 in the YRD region.

Sector 6 (metal and nonmetal products) saw the largest reduction in EEE in the YRD region, decreasing by $83.1 \mathrm{Gg}$ from 2007 to 2012 (Fig. 8b). Local and crossborder linkages were the key linkages affecting the change in this sector. The accelerated decline in 2010-2012 was mainly due to the shift from a local production structure to a cross-border consumption structure. In general, the reduction in pollution emissions in this sector was more dependent on local and cross-border production and consumption restructuring.

Sector 8 (energy) had the largest EEE ratio (37.5\%) in the YRD. As the sector with the largest proportion of local EEE (44.0\%), sector 8 was mainly affected by the local linkage (Fig. 8c). The EEE of sector 8 first experienced a decreasing and then an increasing trend, mainly because of the change in TE and PSE for the local linkage.

With its continuous increase (Fig. 8d), sector 9 (construction) had the largest rate 436 regional EEE linkage (42.7\%). This sector was mainly affected by local and cross437 regional linkages. After 2010, the growth rate of EEE in sector 9 increased more rapidly 438 because of the increase in $C S E$ and $S E$ at the cross-regional scale. In addition, local 439 linkages always maintained a high $S E$, which was also a reason for the continued 440 increase in this sector. 
With a continuous decrease (Fig. 8e), sector 10 (transportation) had the largest

442 reduction rate (16.8\%) in 2007-2012, mainly due to the reduced technical advantage of

443 local, cross-regional and cross-border linkages. The increasing decline was mainly 444 caused by PSE (local linkage) and SE (cross-border linkage).

445 Sector 12 (other services) had the largest increase in EEE (110.2 Gg) and the 446 largest proportion of EEE at the intraregional scale (34.3\%) in the YRD region (Fig. 447 8f). This sector was mainly affected by the loss of $T E$ in the local linkage.

448

449
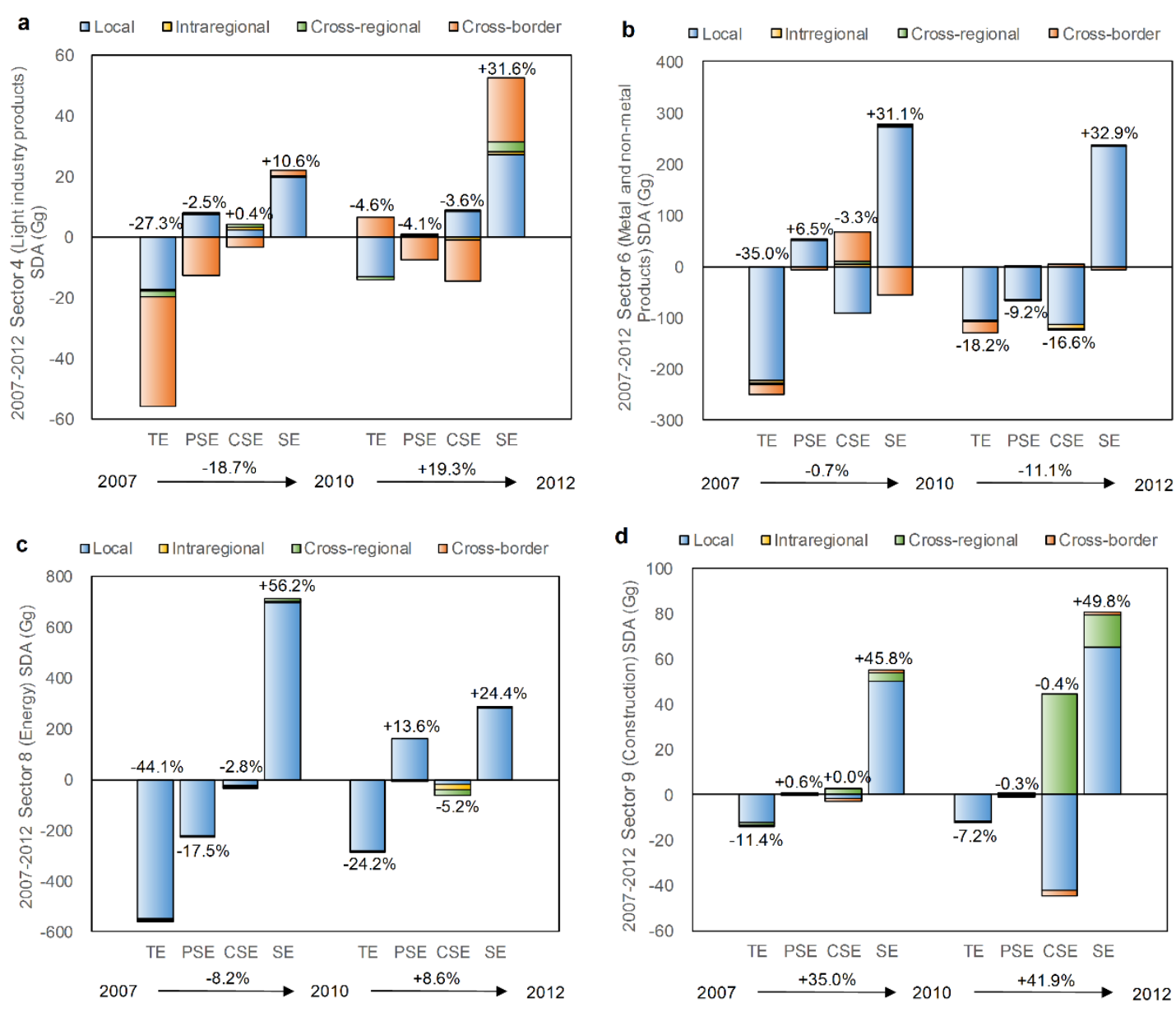

450
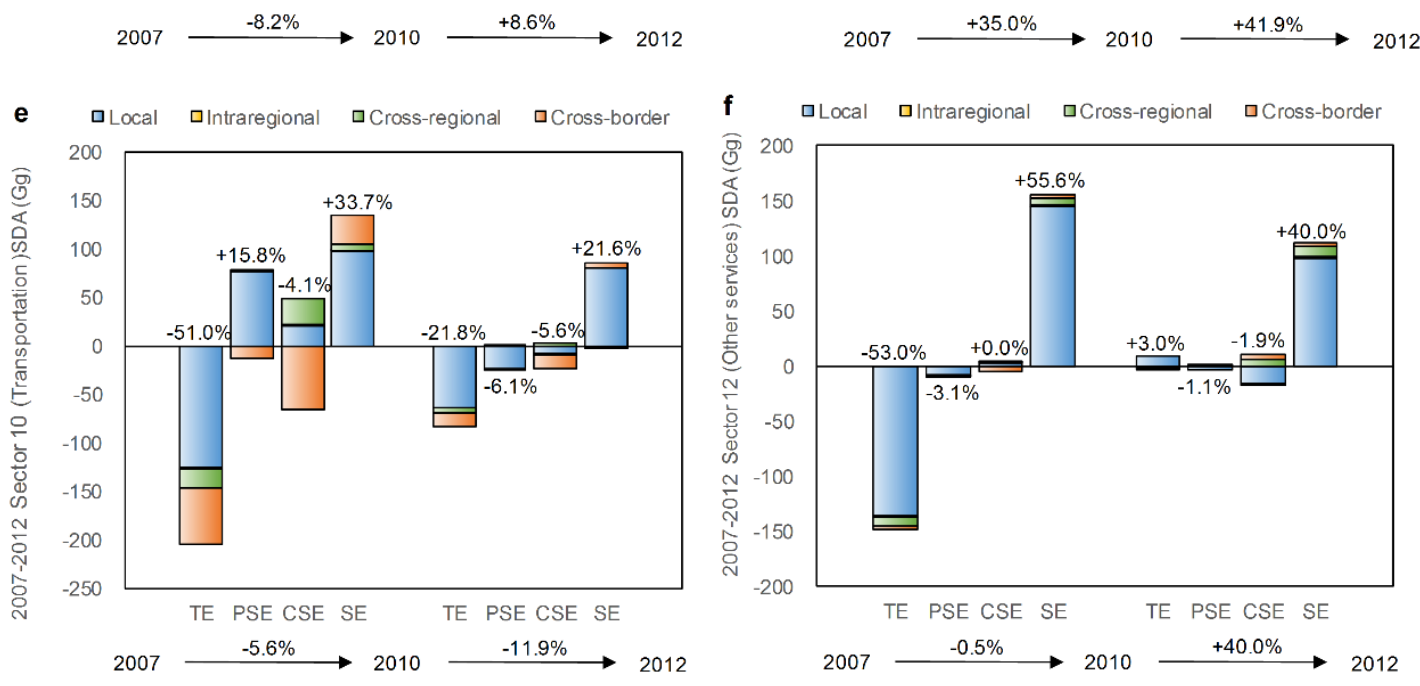
Fig. 8 Structural decomposition analysis (SDA) results for selected sectors from 2007 to 2012. (a) Sector 4 (light industry products), (b) sector 6 (metal and nonmetal products), (c) sector 8 (energy), (d) sector 9 (construction), (e) sector 10 (transportation), and (f) sector 12 (other services). TE means technical effect; PSE means production structure effect; CSE means consumption structure effect; and $S E$ means scale effect.

\section{Discussion}

The MSIO model including intraregional linkages can improve the existing multiscale analytical framework (Chen et al., 2013; Shao et al., 2017). Despite the small EEE within the intraregional linkage in the YRD region, our results show a clear trend of a decrease in intraregional linkage accompanied by an increase in cross-regional linkages. These findings not only expanded our analyses of the scale and sectoral dynamics but also increased our understanding of the region's air pollution and its possible causes.

In particular, the developed MSIO model incorporating intraregional linkage revealed the profound imbalance in the development process of regional integration, reflected in both economic development and pollution emissions. In terms of local EEE linkage in the YRD, the local EEE ratios in Shanghai, Jiangsu and Zhejiang changed from $16 \%$ to $11 \%, 48 \%$ to $55 \%$, and $36 \%$ to $34 \%$, respectively, from 2007 to 2012 (Fig. 4). The proportion of GDP of the three provinces within the YRD was $18 \%, 50 \%$, and $32 \%$, respectively, in 2012 (NBS, 2013). It is clear that the development paths of Shanghai and Zhejiang were greener than that of Jiangsu. These results supported previous research findings that international trade can promote global economic growth but may also exacerbate regional imbalances in internal trade (Daumal, 2013; Zhong et al., 2018). This feature is particularly marked in developing countries (Rivas, 2007). Not only the YRD region but also the developed Beijing-Tianjin-Hebei region (Zhao, et al., 2016a) and the Pearl River Delta region (Zheng et al., 2012) face this development dilemma.

Based on the analytical advantages of the multiscale model constructed in this study, the dynamic performance of the pollution haven hypothesis in the YRD region can be analyzed more accurately and with more details. Judging from the increase in the total amount of embodied pollution in the YRD region, the pollution haven effect increased in the YRD region from 2007 to 2012. However, the pollution haven effect was different 
from various directions outside the YRD region. In other words, the major sources of embodied pollution gradually shifted among linkages. Considering the declines in sector 10 (transportation), sector 4 (light industry products), and sector 6 (metal and nonmetal products), the YRD gradually escaped from the dilemma of the pollution haven hypothesis from cross-border linkage. As mentioned in previous research $(\mathrm{Xu}$ and Song, 2000), due to their comparative advantages, some labor-intensive industries, such as light industry, have shifted from China's east coast to Southeast Asia. Because of the increase in sector 9 (construction) exporting from the YRD to other regions in China, the pollution haven effect from cross-regional linkage was strengthened during the period of 2007-2012. The enhanced cross-regional linkage of the YRD with other regions showed that the inland regions still had a greater dependence on the coastal regions. This result was consistent with Mi and his colleagues' (2017) finding that the carbon emission transfer from China's coast to the inland regions has started to reverse. Therefore, the transformation and upgrade of the economy in coastal areas have not completely transferred the pollution out. The decrease in the intraregional EEE linkage indicates that regional integration in the YRD is oriented toward both the national and international markets. The YRD region tends to be more outward than inward looking (Wu et al., 2017).

In general, the YRD region is still in a transition period and is suffering from increasing environmental pollution due to production and consumption internally and in other regions in China (Yang et al., 2012b). For sustainable development, it is vital to find the key linkages, sectors and factors causing regional environmental pollution

507 (Lu et al., 2015). With the four-level analytical framework, this study effectively 508 identified the key linkages, sectors and factors causing air pollution in the YRD. Based 509 on the results, the following recommendations are proposed. First, more investment is 510 needed from provincial governments to promote local technological innovation (Duan 511 and Jiang, 2017; Zhu et al., 2014). Specifically, more technology innovation is urgently required in the key sectors, including sector 4 (light industry), sector 8 (energy), sector

5139 (construction), sector 10 (transportation) and sector 12 (other services). Second, it is 514 necessary to strengthen pollution taxation (Chen et al., 2015; Yang 2014), especially for 515 sectors oriented toward the local scale, such as sector 4 (light industry) and sector 9 516 (construction). Third, further industry restructuring is necessary to reduce the emissions 517 embodied in cross-border linkages (Lin et al., 2014), especially by adjusting the 518 production and consumption structure of sector 4 (light industry) at the cross-border 
scale. Fourth, for the key export regions of the YRD, such as the middle of the Yellow River and Northeast China, moderate technology transfer could be achieved among regions (Lopez et al., 2019), especially in sector 9 (construction). These recommendations could reduce air pollution in the YRD, other regions in China and even other countries with similar levels of environmental pollution and economic development.

Like many studies, this research has some limitations. First, efforts have been made to collect as much data as possible, but the time series is limited to the data available in the MRIO tables. Second, because this study focused on the exploration of the environmental pressures brought by multiple linkages among a region's EEE, it was difficult to explore the impact of the upstream supply chain through imports. However, improving imports in the upstream supply chain could alleviate regional environmental pressures (Chen et al., 2017). Therefore, more studies are needed targeting the upstream supply chain.

\section{Conclusion}

With worsening air pollution globally, it is important to track the sources of regional air pollutants. A multilevel analytical framework helps analyze and address the embodied emissions problems in a region more comprehensively and with greater detail. This study established a four-level analytical framework (local-intraregional - crossregional-cross-border) of regional EEE, revealing that local and cross-border linkages were the two linkages most crucially affecting EEE in the YRD. To effectively reduce regional environmental pollution, it is necessary to detect the key linkages and key sectors with a multiscale model. In the YRD region, local technological investment must be strengthened in key sectors with the largest proportion of EEE and increasing local linkages, including sector 4 (light industry) and sector 8 (energy). To prevent the region from becoming a pollution haven for developed countries, cross-border EEE linkages need to be reduced by adjusting the production and consumption structure of light industry. Cross-regional EEE linkages can be reduced through technology shifts in the construction sector. Additionally, the trends of a decrease in intraregional linkage and an increase in cross-regional linkage suggest that the development of the YRD has tended to be more outward than inward looking, which clearly described the dynamics of pollution emission in the YRD. 
Compared with the conventional approaches of embodied pollution, the multiscale 552 approach allows for the complexity of one region's economic interdependencies.

553 Moreover, this improved multiscale approach makes it possible to investigate the 554 changing sources of embodied pollution associated with regional development. On this 555 basis, embodied pollution will capture not only the quantitative dynamics but also more 556 sophisticated structural changes. For a region with a high level of openness and 557 economic vitality, this novel multiscale approach is essential for addressing the 558 worsening environmental pollution due to rapid development. The dynamic diagnosis 559 of the emissions embodied in the four linkages indicates that the increasing pollution in 560 the YRD region was dominated by high production demand from the local energy 561 industry, limited local technology innovation, and the dependence of the cross-regional 562 construction industry on consumption. These major findings directly answer the 563 question why the developed YRD region is blocked on in its path to green 564 transformation.

565 The multiscale approach in this study incorporates a new level: the megaregion 566 level. This incorporation is based on a new trend in regional development across the 567 world, where globalization is giving place to regional integration, either globally or 568 locally. Megaregions are playing an increasing role in promoting regional development.

569 The linkages inside and outside the megaregions will further alter the flows of 570 embodied pollutions, which are driven by different determinants. The multiscale 571 approach in this study can identify the internal and external dynamics of economic 572 linkages, indicating that the YRD region gradually transformed from export-oriented 573 growth to endogenous development. Meaningfully, the increase in embodied emissions 574 in the YRD region is accompanied by the weakening of globalization and regional 575 integration. Therefore, this approach is especially meaningful for the core regions 576 within one economy and the transition regions that are shifting from an export-oriented 577 growth model to an endogenous one. 


\section{Appendices}

579 Table A1. Region input-output table for the YRD region

\begin{tabular}{|c|c|c|c|c|c|c|c|c|c|}
\hline & \multirow[t]{2}{*}{ SH } & \multirow[t]{2}{*}{ JS } & \multirow[t]{2}{*}{$\mathrm{ZJ}$} & \multicolumn{3}{|c|}{ Final demand } & Interprovincial export & \multirow{2}{*}{$\begin{array}{l}\text { International } \\
\text { exports }\end{array}$} & \multirow{2}{*}{$\begin{array}{l}\text { Total } \\
\text { export }\end{array}$} \\
\hline & & & & & JS & $\mathrm{ZJ}$ & $\begin{array}{l}\text { Shanxi ... Xinjiang etc. } \\
27 \text { provinces }\end{array}$ & & \\
\hline SH & $Z$ & & & $Y$ & & & $E x$ & & $x$ \\
\hline JS & & & & & & & & & \\
\hline ZJ & & & & & & & & & \\
\hline Value & & & & & & & & & \\
\hline added & $v$ & & & & & & & & \\
\hline $\begin{array}{l}\text { Total } \\
\text { outputs }\end{array}$ & $x^{\wedge}$ & & & & & & & & \\
\hline
\end{tabular}

580 Note: $\mathrm{SH}$ is Shanghai municipality; JS is Jiangsu Province; ZJ is Zhejiang Province 
Table A2. Sector mapping

\begin{tabular}{|c|c|c|}
\hline Code & Aggregated sectors & 30 sectors for Chinese MRIO \\
\hline 1 & Agriculture & Agriculture \\
\hline \multirow[t]{4}{*}{2} & Mining & Coal mining \\
\hline & & Petroleum and gas \\
\hline & & Metal mining \\
\hline & & Nonmetal mining \\
\hline 3 & Foods & Food processing and tobaccos \\
\hline \multirow[t]{4}{*}{4} & Light Industry & Textile \\
\hline & & Clothing, leather, fur, etc. \\
\hline & & Wood processing and furnishing \\
\hline & & Paper making, printing, stationery, etc. \\
\hline \multirow[t]{2}{*}{5} & Chemicals & Petroleum refining, coking, etc. \\
\hline & & Chemical industry \\
\hline \multirow[t]{4}{*}{6} & Metal and Nonmetal & Nonmetal products \\
\hline & Products & Metallurgy \\
\hline & & Metal products \\
\hline & & General and specialist machinery \\
\hline \multirow[t]{5}{*}{7} & Equipment & Transport equipment \\
\hline & & Electrical equipment \\
\hline & & Electronic equipment \\
\hline & & Instrument and meter \\
\hline & & Other manufacturing \\
\hline \multirow[t]{2}{*}{8} & Energy & Electricity and hot water production and supply \\
\hline & & Gas and water production and supply \\
\hline 9 & Construction & Construction \\
\hline 10 & Transport & Transport and storage \\
\hline 11 & $\begin{array}{l}\text { Wholesale and } \\
\text { retailing }\end{array}$ & Wholesale and retailing \\
\hline \multirow[t]{4}{*}{12} & Other services & Hotel and restaurant \\
\hline & & Leasing and commercial services \\
\hline & & Scientific research \\
\hline & & Other services \\
\hline
\end{tabular}


Table A3. Region classifications of 30 provinces in China*

\begin{tabular}{lll}
\hline Abb. & Region & Provinces in the region \\
\hline NE & Northeast & Liaoning, Jilin, Heilongjiang \\
NC & North Coast & Beijing, Tianjin, Hebei, Shandong \\
SC & South Coast & Fujian, Guangdong, Hainan \\
MYR & Middle of the Yellow River & Shanxi, Inner Mongolia, Henan, Shaanxi \\
MCR & Middle of the Yangtze River & Anhui, Jiangxi, Hunan, Hubei \\
SW & Southwest & Chongqing, Sichuan, Yunnan, Guizhou, \\
& & Guangxi \\
NW & Northwest & Gansu, Qinghai, Ningxia, Xinjiang \\
YRD & Yangtze River Delta & Shanghai, Jiangsu, Zhejiang \\
\hline
\end{tabular}

$584 *$ Hong Kong, Macao and Taiwan were excluded due to data limitation. 
Antràs, P., Hillberry, R., 2012. Measuring the upstreamness of production and trade flows. Am. Econ. Rev. 102, 412-416. doi: 10.1257/aer.102.3.412.

Antweiler, W., Copeland, B.R., Taylor, M.S., 2001. Is Free Trade Good for the Environment? Am. Econ. Rev. 91(4), 877-908. doi: 10.1257/aer.91.4.877

Baiocchi, G., Peters, G.P., Roberts, J.T., Steinberger, J.K., 2012. Pathways of human development and carbon emissions embodied in trade. Nat. Clim. Change 2(2), 81-85. doi: 10.1038/NCLIMATE1371

Cai, X., Che, X.H., Zhu, B.Z., Zhao, J., Xie, R. 2018. Will developing countries become pollution havens for developed countries? An empirical investigation in the Belt and Road. J. Clean Prod. 198, 624-632. doi: 10.1016/j.jclepro.2018.06.291

Chen, B., Yang, Q., Zhou, S., Li, J., Chen, G., 2017. Urban economy's carbon flow through external trade: Spatial-temporal evolution for Macao. Energy Policy 110, 69-78. doi: 10.1016/j.enpol.2017.08.010.

Chen G.Q., Guo S, Shao L, Li JS, Chen ZM. 2013. Three-scale input-output modeling for urban economy: Carbon emission by Beijing 2007. Communications in Commun. Nonlinear Sci. Numer. Simul. 18:2493-2506. doi: 10.1016/j.cnsns.2012.12.029

Cheng S.X., Lu K., Liu W., Xiao D. 2019. Efficiency and marginal abatement cost of PM2.5 in China: A parametric approach. J. Clean Prod. 235, 57-68. doi: 10.1016/j.jclepro.2019.06.281

CSC (China State Council), 2013. Action plan for air pollution control. http://www.gov.cn/zhengce/content/2013-09/13/content_4561.htm (accessed on January 22, 2019).

Davis, S.J., Caldeira, K. 2010. Consumption-based accounting of $\mathrm{CO}_{2}$ emissions. Proc. Natl. Acad. Sci. U. S. A. 107(12), 5687-5692. doi: 10.1073/pnas.0906974107

Daumal, M. 2013. The Impact of Trade Openness on Regional Inequality: The Cases of India and Brazil. Int. Trade J. 27(3), 243-280. doi: 10.1080/08853908.2013.796839

Dietzenbacher, E., Los, B. 1998. Structural decomposition techniques: sense and sensitivity. Econ. Syst. Res. 10:4, 307-324. doi: 10.1080/09535319800000023

Duan, Y., Jiang, X. 2017. Temporal change of China's pollution terms of trade and its determinants. Ecol. Econ. 132, 31-44. doi: 10.1016/j.ecolecon.2016.10.001

Feng, K., Davis, S.J., Sun, L., Li, X., Guan, D., Liu, W., Liu, Z., Hubacek, K., 2013. Outsourcing $\mathrm{CO}_{2}$ within China. Proc. Natl. Acad. Sci. U. S. A. 110(28), 1165411659. doi: 10.1073/pnas. 1219918110

Guan, D., Peters, G.P., Weber, C.L., Hubacek, K. 2009. Journey to world top emitter: An analysis of the driving forces of China's recent $\mathrm{CO}_{2}$ emissions surge. Geophys. Res. Lett. 36(4), L04709. doi: 10.1029/2008GL036540 
Guo, J.E., Zhang, Z., Meng, L., 2012. China's provincial $\mathrm{CO}_{2}$ emissions embodied in international and interprovincial trade. Energy Policy 42(C), 486-497. doi: 10.1016/j.enpol.2011.12.015

Han, M.Y., Chen, G.Q., Mustafa, M.T., Hayat, T., Shao, L., Li, J.S., Xia ,X.H., Ji „X. 2015. Embodied water for urban economy: a three-scale input-output analysis for Beijing 2010. Ecol. Model. 318:19-25. doi:10.1016/j.ecolmodel.2015.05.024

Hubacek, K., Feng, K., Minx, J.C., Pf ister, S., Zhou, N. 2014. Teleconnecting consumption to environmental impacts at multiple spatial scales. J. Ind. Ecol. 18(1), 7-9. doi: 10.1111/jiec. 12082

Lan, J., Malik, A., Lenzen, M., Mcbain, D., Kanemoto, K., 2016. A structural decomposition analysis of global energy footprints. Appl. Energy 163, 436-451. doi: 10.1016/j.apenergy.2015.10.178

Lopez, L.A., Cadarso, M.A., Zafrilla, J., Arce, G. 2019. The carbon footprint of the US multinationals' foreign affiliates. Nat. Commun. 10, 1672. doi: 10.1038/s41467019-09473-7

Leontief, W., 1974. Environmental Repercussions and the Economic Structure: An Input-Output Approach: A Reply. Rev. Econ. Stat. 56(1), 109-110. doi: $10.2307 / 1927535$

Li, F., Xiao, X., Xie, W., Ma, D., Song, Z., Liu, K. 2018. Estimating air pollution transfer by interprovincial electricity transmissions: The case study of the Yangtze River Delta Region of China. J. Clean Prod. 183, 55-56. doi: 10.1016/j.jclepro.2018.01.190

Li, J.S., Xia, X.H., Chen, G.Q., Alsaedi, A., Hayat, T. 2016. Optimal embodied energy abatement strategy for Beijing economy: Based on a three-scale input-output analysis. Renew. Sust. Energ. Rev. 53:1602-1610. doi: 10.1016/j.rser.2015.09.090

Li, M., Zhang, Q., Streets, D.G., He, K.B., Cheng, Y.F., Emmons, L.K., Huo, H., Kang, S.C., Lu, Z., Shao, M., Su, H., Yu, X., Zhang, Y., 2014. Mapping Asian anthropogenic emissions of non-methane volatile organic compounds to multiple chemical mechanisms. Atmos. Chem. Phys. 14, 5617-5638. doi: 10.5194/acp-145617-2014

Li, M., H. Liu, G. N. Geng, C. P. Hong, F. Liu, Y. Song, D. Tong, B. Zheng, H. Y. Cui, H. Y. Man, Q. Zhang, He, K.B. 2017. Anthropogenic emission inventories in China: a review, Natl. Sci Rev. 4, 834-866. doi: 10.1093/nsr/nwx150

Li Y.L., Han M.Y., Liu S.Y., Chen, G.Q. 2019. Energy consumption and greenhouse gas emissions by buildings: A multi-scale perspective. Build. Environ. 151, 240-250. doi: 10.1016/j.buildenv.2018.11.003.

Li, Y.L., Chen, B., Han, M.Y., Dunford, M., Liu, W., Li, Z. 2018a. Tracking carbon transfers embodied in Chinese municipalities' domestic and foreign trade. J. Clean Prod. 192, 950-960. doi: 10.1016/j.jclepro.2018.04.230.

Li, J., Huang, X., Kwan, M.P., Yang, H., Chuai, X. 2018b. The effect of urbanization on carbon dioxide emissions efficiency in the Yangtze River Delta, China. J. Clean Prod. 188, 38-48. doi: 10.1016/j.jclepro.2018.03.198 
Lin J, Hu Y, Zhao X, Shi L, Kang J. 2017. Developing a city-centric global multiregional input-output model (CCG-MRIO) to evaluate urban carbon footprints. Energy Policy 108:460-466. doi: 10.1016/j.enpol.2017.06.008

Lin, J., Pan, D., Davis, S.J., Zhang, Q., He, K., Wang, C., Streets, D.G., Wuebbles, D.J., Guan, D., 2014. China's international trade and air pollution in the United States, Proc. Natl. Acad. Sci. U. S. A. 111(5), 1736-1741. doi: 10.1073/pnas.1312860111

Liu, M., Huang, Y., Ma, Z., Jin, Z., Liu, X., Wang, H., Liu, Y., Wang, J., Jantunen, M., Bi, J., Kinney, P. 2017. Spatial and temporal trends in the mortality burden of air pollution in China: 2004-2012. Environ. Int. 98, 75-81. doi: 10.1016/j.envint.2016.10.003

Liu, F., Zhang, Q., Tong, D., Zheng, B., Li, M., Huo, H., He, K.B. 2015. High-resolution inventory of technologies, activities, and emissions of coal-fired power plants in China from 1990 to 2010, Atmos. Chem. Phys. 15, 13299-13317. doi:10.5194/acp15-13299-2015

Liu, Q., Wang, Q., 2015. Reexamine $\mathrm{SO}_{2}$ emissions embodied in China's exports using multiregional input-output analysis. Ecol. Econ. 113, 39-50. doi: 10.1016/j.ecolecon.2015.02.026

Liu, Q., Wang, Q., 2017. Sources and flows of China's virtual $\mathrm{SO}_{2}$ emission transfers embodiedin interprovincial trade: A multiregional inputeoutput analysis. J. Clean Prod. 161, 735-747. doi: 10.1016/j.jclepro.2017.05.003

Liu, W., Chen, J., Tang, Z., Liu, H., Han, D., Li, F., 2012. The theory and practice of compiling Multi-regional input-output model for 30 provinces of China in 2007. China Statistics Press, Beijing.

Liu, W., Tang, Z., Chen, J., Yang, B., 2014. Multi-regional input-output model for 30provinces of China in 2010. China Statistics Press, Beijing.

Lu, Q.L., Yang, H., Huang, X.J., Chuai, X.W., Wu, C.Y., 2015. Multi-sectoral decomposition in decoupling industrial growth from carbon emissions in the developed Jiangsu Province, China. Energy 82, 414-425. doi: 10.1016/j.energy.2015.01.052

Mao, X., He, C., 2017. Export upgrading and environmental performance: Evidence from China. Geoforum (86), 150-159. doi: 10.1016/j.geoforum.2017.09.010

Mao, X., He, C., 2019. Product relatedness and export specialisation in China's regions: A perspective of global-local interactions. Camb. J. Regions Econ. Soc. 12(1):105126. doi: 10.1093/cjres/rsy031.

Meng, B., Xue, J., Feng, K., Guan, D., Fu, X., 2013. China’s inter-regional spillover of carbon emissions and domestic supply chains. Energy Policy 61, 1305-1321. doi: 10.1016/j.enpol.2013.05.108

Meng, H., Huang, X., Yang, H., Chen, Z., Yang, J., Zhou, Y., Li, J., 2019. The influence of local officials' promotion incentives on carbon emission in Yangtze River Delta, China. J. Clean Prod. 213(2019), 1337-1345. doi: 10.1016/j.jclepro.2018.12.036 
Meng, J., Mi, Z., Guan, D., Li, J., Tao, S., Li, Y., Feng, K., Liu, J., Liu, Z., Wang, X., Zhang, Q., Davis, S.J. 2018. The rise of South-South trade and its effect on global CO2 emissions. Nat. Commun. 9, 1871. doi: 10.1038/s41467-018-04337-y

Mi, Z., Meng, J., Guan, D., Shan, Y., Song, M., Wei, Y.-M., Liu, Z., Hubacek, K. 2017. Chinese $\mathrm{CO}_{2}$ emission flows have reversed since the global financial crisis. Nat. Commun. 8, 1712. doi: 10.1038/s41467-017-01820-w

Mi, Z., Meng, J., Green, F., Coffman, D.M., Guan, D. 2018. China's "Exported Carbon" Peak: Patterns, Drivers, and Implications. Geophys. Res. Lett. 45(9), 4309-4318. doi: 10.1029/2018GL077915

NBS (National Bureau of Statistics), 2013. China Statistical Yearbook 2012. China Statistics Press, Beijing.

NBS (National Bureau of Statistics). 2018. China Statistical Yearbook 2017. China Statistics Press, Beijing.

NDRC (National Development and Reform Commission), 2016. Development plan of Yangtze river delta urban agglomeration. http://www.ndrc.gov.cn/zcfb/zcfbghwb/201606/t20160603_806390.html (accessed on January 22, 2019).

Pan, J., Phillips, J., Chen, Y., 2008. China's balance of emissions embodied in trade: approaches to measurement and allocating international responsibility. Oxf. Rev. Econ. Policy 24(2), 354-376. doi: 10.1093/oxrep/grn016

Peters, G.P., Hertwich, E.G., 2006. Pollution embodied in trade: The Norwegian case. Glob. Environ. Change-Human Policy Dimens. 16(4), 379-387. doi: 10.1016/j.gloenvcha.2006.03.001

Rivas, M.G., 2007. The effects of trade openness on regional inequality in Mexico. Ann. Reg. Sci. 41(3), 545-561. doi: 10.1016/j.gloenvcha.2006.03.001

SDPC (State Development Planning Commission), MF (Ministry of Finance), SEPA (State Environmental Protection Administration), SETC (State Economic and Trade Commission), 2003. Measures for Levy Standard on Pollutant Discharge Fee. $\quad$ http://zfs.mee.gov.cn/gz/bmgz/qtgz/200302/t20030228_86250.shtml . (accessed on January 22, 2019).

Shao L., Guan D., Zhang N., Shan Y., Chen G.Q. 2016. Carbon emissions from fossil fuel consumption of Beijing in 2012. Environ. Res. Lett. 11, 114028. doi: 10.1088/1748-9326/11/11/114028

Shao, L., Guan, D., Wu, Z., Wang, P., Chen, G.Q., 2017. Multi-scale input-output analysis of consumption-based water resources: Method and application. J. Clean Prod. 164, 338-346. doi: 10.1016/j.jclepro.2017.06.117

Stern, D.I., 2004. The Rise and Fall of the Environmental Kuznets Curve. World Dev. 32(8), 1419-1439. doi: 10.1016/j.worlddev.2004.03.004

$\mathrm{Su}$, B., Thomson, E. 2016. China's carbon emissions embodied in (normal and processing) exports and their driving forces, 2006-2012. Energy Econ. 59, 414422. doi:10.1016/j.eneco.2016.09.006 
Wang, Y., Zhao, T., 2015. Impacts of energy-related $\mathrm{CO}_{2}$ emissions: evidence from under developed, developing and highly developed regions in China. Ecol. Indic. 50, 186-195. doi: 10.1016/j.ecolind.2014.11.010

Wu, C., Wei, Y.D., Huang, X., Chen, B., 2017. Economic transition, spatial development and urban land use efficiency in the Yangtze River Delta, China. Habitat Int. 63, 67-78. doi: 10.1063/1.4926803

$\mathrm{Xu}$, X., Song, L., 2000. Regional Cooperation and the Environment: Do "Dirty" Industries Migrate? Weltwirtsch. Arch.-Rev. World Econ. 136(1), 137-157. doi: 10.1007/BF02707399

Xu, Y., Dietzenbacher, E., 2014. A structural decomposition analysis of the emissions embodied in trade. Ecol. Econ. 101(5), 10-20. doi: 10.1016/j.ecolecon.2014.02.015

Xu, X., Yang, G., Tan, Y., Zhuang, Q., Tang, X., Zhao, K., Wang, S. 2017. Factors influencing industrial carbon emissions and strategies for carbon mitigation in the Yangtze River Delta of China. J. Clean Prod. 142, 3607-3616. doi: 10.1016/j.jclepro.2016.10.107

Yang, H., 2014. China must continue the momentum of green law. Nature 509, 535535. doi:10.1038/509535a

Yang, H., Flower, R.J., Thompson, J.R., 2012a. Rural factories won't fix Chinese pollution. Nature 490(7420), 342. doi: 10.1038/490342d

Yang, H., Xie, P., Ni, L., Flower, R.J., 2012b. Pollution in the Yangtze. Science 337, 410-410. doi: 10.1126/science.337.6093.410-a

Yang, H., Huang, X., Thompson, J.R., Flower, R.J., 2015. Enforcement key to China's environment. Science, 347(6224), 834-835. doi: 10.1126/science.347.6224.834-d

Yang, J., Wang, J., 1998. Reforming and Design of Pollution Levy System in China. China Environmental Science Press, Beijing.

Yang, X., Feng, K.S., Su, B., Zhang, W.Z., Huang, S. 2019a. Environmental efficiency and equality embodied in China's inter-regional trade. Science of the Total Environment 672, 150-161. doi: 10.1016/j.scitotenv.2019.03.450.

Yang, W., Yuan, G., Han, J. 2019b. Is China's air pollution control policy effective? Evidence from Yangtze River Delta cities, J. Clean Prod. doi: 10.1016/j.jclepro.2019.01.287.

Zhang, W., Wang, F., Hubacek, K., Liu, Y., Wang, J., Feng, K., Jiang, L., Jiang, H., Zhang, B., Bi, J., 2018a. Unequal Exchange of Air Pollution and Economic Benefits Embodied in China's Exports. Environ. Sci. Technol. 52(7), 3888-3898. doi: 10.1021/acs.est.7b05651

Zhang, W., Liu, Y., Feng, K., Hubacek, K., Wang, J., Liu, M.M., Jiang, L., Jiang, H., Liu, N., Zhang, P., 2018b. Revealing Environmental Inequality Hidden in China's Inter-Regional Trade. Environ. Sci. Technol. 52(13), 7171-7181. doi: 10.1021/acs.est.8b00009

Zhang, Q., Jiang, X., Tong, D., Davis, S.J., Zhao, H., Geng, G., Feng, T., Zheng, B., Lu, Z., Streets, D.G., Ni, R., Brauer, M., van Donkelaar A., Martin, R.V., Huo, H., Liu, 

Z., Pan, D., Kan, H., Yan, Y., Lin, J., He K., Guan, D. 2017. Transboundary health impacts of transported global air pollution and international trade. Nature, 543(7647), 705-709. doi:10.1038/nature21712

Zhao, H.Y., Zhang, Q., Guan, D.B., Davis, S.J., Liu, Z., Huo, H., Lin, J.T., Liu, W.D., He, K.B. 2015. Assessment of China's virtual air pollution transport embodied in trade by using a consumption-based emission inventory, Atmos. Chem. Phys. 15, 5443-5456, doi:10.5194/acp-15-5443-2015

Zhao, H.Y., Zhang, Q., Huo, H., Lin, J., Liu, Z., Wang, H., Guan, D., He, K., $2016 a$. Environment-economy tradeoff for Beijing-Tianjin-Hebei's exports. Appl. Energy 184, 926-935. doi: 10.1016/j.apenergy.2016.04.038

Zhao, Y., Wang, S., Zhang, Z., Liu, Y., Ahmad, A., 2016b. Driving factors of carbon emissions embodied in China-US trade: a structural decomposition analysis. J. Clean Prod. 131, 678-689. doi: 10.1016/j.jclepro.2016.04.114

Zheng, J., He, M., Shen, X., Yin, S., Yuan, Z., 2012. High resolution of black carbon and organic carbon emissions in the Pearl River Delta region, China. Sci. Total Environ. 438(3), 189-200. doi: 10.1016/j.scitotenv.2012.08.068

Zheng, J.J., Jiang, P., Qiao, W., Zhu, Y., Kennedy, E. 2016. Analysis of air pollution reduction and climate change mitigation in the industry sector of Yangtze River Delta in China. J. Clean Prod. 114, 314-322. doi: 10.1016/j.jclepro.2015.07.011

Zhong, Z., He, L., Wang, Z., 2017. Geographic sources and the structural decomposition of emissions embodied in trade by Chinese megacities: The case of Beijing, Tianjin, Shanghai, and Chongqing. J. Clean Prod. 158, 59-72. doi: 10.1016/j.jclepro.2017.04.148

Zhong, Z., Jiang, L., Zhou, P., 2018. Transnational transfer of carbon emissions embodied in trade: Characteristics and determinants from a spatial perspective. Energy 147, 858-875. doi: 10.1016/j.energy.2018.01.008

Zhu, X.H., Zou J.W., Feng, C. 2017. Analysis of industrial energy-related CO2 emissions and the reduction potential of cities in the Yangtze River Delta region. J. Clean Prod. 168, 791-802. doi: 10.1016/j.jclepro.2017.09.014

Zhu, S., He, C., Liu, Y., 2014. Going green or going away: Environmental regulation, economic geography and firms' strategies in China's pollution-intensive industries. Geoforum, 53-65. doi: 10.1016/j.geoforum.2014.05.004 